This is the peer reviewed version of the following article: Dockery, A.M. and Bawa, S. 2015. The Impact of Children on Australian Couples' Wealth Accumulation. Economic Record. 91 (S1): pp. 139150, which has been published in final form at http://doi.org/10.1111/1475-4932.12194. This article may be used for non-commercial purposes in accordance with Wiley Terms and Conditions for SelfArchiving at http://olabout.wiley.com/WileyCDA/Section/id-820227.htm/\#terms 


\title{
The Impact of Children on Australian Couples' Wealth Accumulation
}

\begin{abstract}
Existing estimates of the cost of children focus on what parents spend on their children, which has limited relevance to parents' financial capacity to meet those costs. An alternative indicator of the affordability of children - their impact upon couples' wealth accumulation is estimated using the life-cycle model and Australian household panel data. The results suggest children have a very small impact upon wealth accumulation, seemingly at odds with the large 'costs' implied from expenditure-based estimates. In reconciling these highly divergent estimates we argue the net-wealth approach is an intuitively more appealing indicator of the financial impost of children.
\end{abstract}

Keywords: children, family, wealth, lifecycle model, savings

JEL classifications: J13, J22, I32

This paper uses unit record data from the Household, Income and Labour Dynamics in Australia (HILDA) Survey. The HILDA Project was initiated and funded by the Australian Government Department of Social Services (DSS) and is managed by the Melbourne Institute of Applied Economic and Social Research (the Melbourne Institute). The findings and views reported in this paper, however, are those of the authors and should not be attributed to either DSS or the Melbourne Institute. 


\section{Introduction}

It has been well established that strong inter-generational gradients exist in health outcomes and in socio-economic status more generally (Case, Lubotsky \& Paxson, 2002; Commission on Social Determinants of Health, 2008; Hertzman, 1999). Hence any society that values equality in opportunity for upcoming generations should also care about families' resource requirements when bringing up children. Having an appreciation of families' financial capacity to meet these requirements is important to the design of various economic and social policies; including income support programs, guidelines for child support obligations for noncustodian parents, programs to encourage fertility rates, and for making comparisons of standards of living or setting poverty lines for families with different numbers of children (Garvey, Murphy \& Osikoya, 2011; Gray \& Stanton, 2010; Percival \& Harding, 2007; Valenzuela, 1999).

Saunders emphasised, "clearly there is an ongoing need to ensure that the best possible estimates of the costs of children are available so as to inform public debate and policy formulation on these important issues" (1999: p. 63). To meet this need a number of different approaches have been used to generate quantitative estimates of the costs of children. Most commonly these are based on how much families actually spend on children (the expenditure approach) or how much is 'needed' to be spent (the budget standards approach or equivalent standard of living approach). Existing empirical estimates for Australia and other developed countries suggest that children impose a very substantial cost upon their parents, with estimates of the annual cost of raising a child typically exceeding US $\$ 10,000$.

Note, however, that expenditure associated with children does not correspond directly to parents' financial capacity to meet those requirements. From both a private and social policy perspective, the important issue surrounding the financial impost of raising children is that of 'affordability', which may be better thought of in terms of the extent to which children impact upon parents' financial wellbeing, or contribute to financial stress.

In this paper, we question the relevance of measures of the 'cost' of children to the more critical question of affordability. Drawing upon the life cycle model, we propose an alternative approach to estimating the affordability of children based on differences in wealth accumulation conditional on the number of children couples have had, and provide estimates of this wealth impact of children using Australian household panel data. The empirical estimates based on this 'net wealth' approach imply children have a far lower impost upon 
financial wellbeing than has been suggested by existing estimates based on other commonly used approaches. In reconciling these vastly different results we argue that the wealth approach is an intuitively more appealing indicator of the affordability of children on a number of fronts, and discuss the implications for policy and for families.

\section{Background}

Only a limited number of studies have analysed the impact of children on wealth accumulation, including Bolin and Palsson (2001) and Scholz and Seshandri (2009), the latter noting in their abstract "The fact that there are few papers on this topic is puzzling, since children have implications for optimal retirement planning for nearly every American household." In contrast, numerous studies have generated estimates of the cost of raising children. While both these quanta provide perspectives on affordability, and in fact are inextricably linked, to our knowledge no previous paper has contrasted the findings from the two approaches in terms their implications for the impact of children on parent's financial wellbeing.

In this section we argue that on a number of grounds estimates of the impact of children on wealth is a more meaningful gauge of the financial impost of children on their parents. First, the main approaches used to assess the cost of children and their associated empirical estimates are reviewed, with a bias towards Australian studies, as our own analysis is based upon household data from that country. A discussion of the limitations of these approaches as a measure of affordability follows and an alternative measure, based on couple's wealth accumulation, is proposed.

\section{(i) Estimating the cost of children}

The main approaches used to estimate the cost of children are the expenditure approach, the budget standards approach and the equivalent living standard approach. The expenditure approach simply sums the amount of money that parents spend on their children, although some studies also consider non-monetary 'expenditure', such as parental time. The budget standards approach identifies a 'basket of goods' deemed necessary to guarantee a certain standard of living, typically a poverty line, for families of different size. The equivalent living standard approach seeks to identify the compensating level of income required for a couple with differing numbers of children to maintain the same level of utility as a like 
couple without children. The key methodological challenge for the budget standards approach is how to determine the equivalence scales to compare the requirements of different families. The equivalent living standards approach implies knowledge of the parents' underlying utility function. In reality the utility function cannot be observed, and preferences are often approximated through a system of demand equations for household budget items conditional upon income and family composition.

Examples of Australian studies that follow the expenditure approach include a series of reports produced by the National Centre for Social and Economic Modelling (Percival and Harding 2002, 2005 \& 2007; NATSEM 2013). The most recent of these estimated that a typical middle-income Australian family spends A $\$ 812,000$ on raising two children from birth to 21 years. This represents an annual figure of around $\mathrm{A} \$ 19,300$ per child-year, a 50 per cent increase on Percival and Harding's 2007 estimate. Following the budget standards approach, Henman (2008) produces estimates for each capital city. Estimates of the annual cost of raising one child to age 18 in Sydney, the cheapest of the capitals, ranges from $\mathrm{A} \$ 6,700$ at a 'low cost' living standard to $\mathrm{A} \$ 12,100$ at a 'modest but adequate' living standard.

Results are often presented in terms of the implied equivalence scales that would equate welfare between families of different size. Recent Australian studies include Bradbury (2008), which concluded that a two-child family requires a money income 1.4 times that of a couple without children. Gray and Stanton (2010) averaged the results of equivalence scales for post-1985 Australian studies to find a range from 1.16 to 1.23 for a family with one child depending upon the methods used, increasing to between 1.58 and 1.63 for a family with three children, relative to a childless couple.

Based on the expenditure approach, estimates of the annual cost of raising a child of US\$12,290 to US\$14,320 for a middle income group have been derived for the US (Lino 2012) and $£ 10,400$ per annum in the U.K. from birth to age 21 (' $L V=$ ', 2012). Using the basket of goods approach, Garvey et al. (2011) estimate that a couple in Ireland with one child would need 22 per cent more income to be as well off as a childless couple, a figure they claim to be broadly consistent with previous Irish and international estimates using a comparable methodology.

There are a number of technical issues relating to these approaches. For example, the commonly used method of standardising living standards across households based on the 
proportion of household income spent on food, first proposed by Engel in 1895, is thought to over-estimate the cost of children since, unlike housing, there is less scope for joint consumption of food. Numerous previous papers have canvassed these limitations (see, for example, Deaton \& Muellbauer, 1986; Gray \& Stanton, 2010; McDonald, 1990; Pollak \& Wales, 1979; Saunders 1999) and here we focus instead on the conceptual basis for considering money spent on children as an (inverse) indicator of affordability.

\section{(ii) A net-wealth approach to affordability}

For a number of reasons expenditure-based estimates of the cost of raising children do not translate directly to the key issue of affordability, or the capacity of parents to meet those resource requirements. These reasons are explored more fully in the concluding discussion, but for now we draw attention to three key limitations to argue that the impact of children on the net wealth of families provides a more intuitively appealing indication of affordability. Perhaps the most important of these, from a conceptual perspective, is that children provide benefits as well as costs (Ferreira, Buse \& Chavas, 1998; Pollak \& Wales, 1979; Scholz \& Seshadri, 2009). It is a well-known identity in economics that a household's income in any period is equal to consumption plus savings. Income can either be spent or saved. If the expenditure on children displaces, dollar for dollar, parents' consumption on other goods and services, but parents derive exactly the same utility from the presence of children as from that other consumption bundle, then clearly the parents' wellbeing is no lower. Accordingly, the parents are financially neither better nor worse off due to the presence of children, and this would be reflected in the children having no impact on net wealth (savings) as total expenditure is unchanged. If, instead, the consumption foregone for each dollar spent on children left parents with lower utility, the marginal utility received from increasing their own consumption would be higher, and they would increase total consumption leading to lower savings and lower wealth.

Second, in many countries families with dependent children receive a range of benefits in the form of additional social security allowances, tax concessions and recently, in the case of Australia, even a 'baby bonus' financial payment upon the birth of a child. To the extent that income increases as a result of having children, the impact on affordability is lessened. And finally, one of the major financial impacts of children is surely the opportunity cost of foregone income incurred as a result of family commitments, typically the mother's time out of the labour force. The effect of these changes on the income side of the equation upon the 
parents' financial wellbeing are ignored in expenditure approaches, but are well accounted for by assessing the impact of children on net wealth.

We identified only two existing studies that estimate the impact of children on net wealth. Scholz and Seshandri (2009) estimate that each additional child a family has had reduced net wealth of American families in 1992 by US\$6,384 based on a mean regression, or by US $\$ 2,601$ based on a median regression. The impact on wealth on a 'per child-year' basis must therefore be very small. Bolin and Palsson (2001) find that the impact of children on wealth accumulation in Sweden varies markedly according to parents' gender and marital status (single, cohabiting or married) but find children to actually have a positive effect on wealth for married men and women. Both of these studies are based on the lifecycle model, to which we now turn.

\section{Method}

\section{(i) The Life Cycle model}

As a theoretical framework in which to analyse the impact of children on family wealth we draw upon the Life Cycle Hypothesis (LCH) attributed to Modigliani and Brumberg (1954). The basic LCH starts with the theory that, in seeking to maximise lifetime utility, individuals (or families) will smooth their consumption over the lifecycle. Thus, in periods when income is higher than the life-time average flow of income individuals will save, and dissaving will occur in periods in which income is lower than average. Both income and consumption typically follow a 'hump' shape over the life-cycle, but the consumption profile is less humped. Most obviously, people accumulate wealth during their peak working and earning years, and run wealth down during retirement as consumption exceeds income.

The LCH is not without a number of challenges, including debate on the importance of bequests (Modigliani, 1986) and the observed drop in consumption upon retirement that seems inconsistent with consumers acting with such foresight (Banks, Blundell \& Preston, 1994). However, the basic theory leads to important micro- and macro-economic predictions that have found broad empirical support. Examples include the relative insensitivity of consumption to current income which is more consistent with Friedman's (1957) Permanent Income Hypothesis than the Keynesian consumption function; and aggregate savings at the 
national level being positively associated with the rate of growth of per capita income rather than the level of per-capita income (see, for example, Deaton, 2005; Modigliani, 1986).

In terms of the effects of the impact of children, because consumption is assumed to be higher when children are present, the LCH predicts that savings will be lower at each age following the arrival of children (and with the number of children), and in particular net savings will be lower (or dissavings greater) during the years of child-rearing. According to Modigliani, in his Nobel Prize address “... available evidence supports the LCH prediction that the amount of net worth accumulated up to any given age in relation to life resources is a decreasing function of the number of children, and that saving tends to fall with the number of children present in the household and to rise with the number of children no longer present" (1986, p. 304). In effect, children were seen to postpone or replace saving for retirement (Banks et al., 1994; Deaton, 2005). However, it should be noted that the significant increase in the age at which women now bear children from the time Modigliani formulated the LCH is likely to have altered these dynamics, offering more scope for families to accumulate wealth in anticipation of having children and to smooth consumption over the life-cycle.

\section{(ii) Data and model}

To estimate the magnitude of these impacts data from the Household, Income and Labour Dynamics in Australia Survey (HILDA) are used to model, firstly, net wealth accumulation of couples over the life-cycle conditional on the number of children they have had and, secondly, changes in wealth over four-yearly intervals conditional on the presence of children. The HILDA Survey is a longitudinal survey of a representative sample of Australian households, with interviews completed annually. The set of survey instruments includes a Household Questionnaire administered to an adult member of the household and collecting information about the household unit; and individual surveys with each member of the household aged 15 or over. Data from the first ten waves of the survey, spanning the years 2001 to 2010, were available for analysis for this paper. Around 13,000 individuals from over 7,000 households have responded in each year, with year on year attrition rates averaging below 10 per cent. Detailed information on the HILDA sampling frame and survey can be found at the HILDA website (http://www.melbourneinstitute.com/hilda/) and in Watson and Wooden (2010). 
In the 2002, 2006 and 2010 waves of the survey the Household Questionnaire included a 'wealth module' which collected extensive information on assets and liabilities, permitting the derivation of a 'net wealth' variable. In addition, HILDA contains a host of other variables on individual and household characteristics, including detailed information on educational attainment, labour market activities and history, and relationships. Initially a model of net wealth is estimated across the pooled-cross section of couples who are living together in a registered marriage as observed in 2002, 2006 and 2010. The sample is restricted to exclude couples living with people other than their dependent children. Potentially the one family could contribute three observations to the dataset. The model is of the form:

$$
Y_{j t}=\alpha_{1}+\beta_{1} X_{j t}+\gamma_{1} C_{j t}+\epsilon_{j t}
$$

with subscript $\mathrm{j}$ denoting families and $t=2002,2006,2010$. Net wealth $\left(\mathrm{Y}_{\mathrm{jt}}\right)$ is indexed using the Australian consumer price index to be expressed in 2010 dollars, and $\alpha_{1}$ is a constant term. The vector $\mathrm{X}_{\mathrm{jt}}$ encompasses variables capturing the stage of the lifecycle (age, age-squared and duration of the current marriage) and other characteristics likely to impact upon permanent income, or long-term earnings capacity, and wealth accumulation (level of education, work experience, disability status and whether from non-English speaking background and English proficiency, having been in a previous marriage). $\beta_{1}$ is the associated vector of parameters to be estimated.

The variable $C_{j t}$ is the proxy for child-years with associated parameter $\gamma_{1}$ to be estimated. $C_{j t}$ is calculated as the number of children the female in the couple has ever had multiplied by 18 , but adjusted for the number and age of children currently living in the home at the time of the survey (so a 2 year old living in the family, for example, contributes 2 years rather than 18 years to this sum). While using the pooled cross-sections generates a larger sample of families for the estimation, only this rough approximation of the number of years in which the family has had children living in the home can be calculated. This limitation is addressed in the model 2 , in which the dependent variable is the change in wealth over the four years between the wealth modules. In this case, it is possible to derive from the survey data exactly how many children resided with the family in each year, as follows: 


$$
Y_{j t+4}-Y_{j t}=\alpha_{2}+\delta Y_{j t}+\beta_{2} X_{j t}+\gamma_{2} \sum_{t+1}^{t+4} C_{j t}+\epsilon_{j t}
$$

with $\mathrm{t}=2002$, 2006. Hence, the dataset now represents a pooling of two sets of observations: those on changes in wealth between 2002 and 2006, and those on changes in wealth between 2006 and 2010. The summation $\sum_{t+1}^{t+4} C_{j t}$ is the sum of the number of children living with the family in each of the four intervening years. That is, the sum of number of children present in 2003, 2004, 2005 and 2006 for $\mathrm{t}=2002$; and in 2007, 2008, 2009 and 2010 for $\mathrm{t}=2006$.

For each of those periods the sample is restricted to couples who remained married to one another for the four years, and a family can potentially contribute two observations to the estimation. The initial wealth holding at the commencement of the period is now added to the set of control variables and, as noted, the construction of more precise measures of the extent of child rearing during the periods are now possible. The only age restriction imposed is that both the wife and husband of the couple are aged 18 years or over.

For both models 1 and 2, a standard ordinary least squares regression model is first estimated, followed by quantile regression at the $0.25,0.5$ and 0.75 quantiles of the distribution for net wealth and the change in wealth, respectively. Whereas conventional OLS estimates the effect of a covariate on the conditional mean of the dependent variable, quantile regression, attributed to Koenker and Bassett (1978), produces estimates of the effect of the variable at other points (quantiles) of the distribution. This is informative in cases in which the effect of variables might be expected to vary at different points of the distribution, plus quantile regression is known to be less sensitive to outliers or extreme values of the dependent variable (see Koenker \& Hallock, 2001). Both these attributes are likely to be useful for the current application. All models were estimated using the STATA statistical software Version 12 (the sqreg routine in the case of the quantile regressions).

For brevity, only the results for the preferred specification are reported for both models 1 and 2 , with a discussion of the sensitivity of the results to alternative specifications presented below. A total of 8,804 observations were available for estimation for model 1 and 4,286 for model 2, reduced from initial samples of 9,120 and 4,551, respectively, after removing observations that have missing values for some variables. 


\section{Results}

Figure 1 depicts the general pattern of wealth accumulation over the lifecycle for married Australian couples. It is derived from the pooled cross-section of couples by averaging derived net wealth for 5-year age cohorts based on the average age of the couple. It can be seen that net wealth follows the savings and dissavings pattern as predicted by the $\mathrm{LCH}$, with net wealth peaking at around A $\$ 1.3$ million at age 60-65.

Figure 1: Wealth of the life-cycle, married Australian couples; 2002, 2006 and 2010.

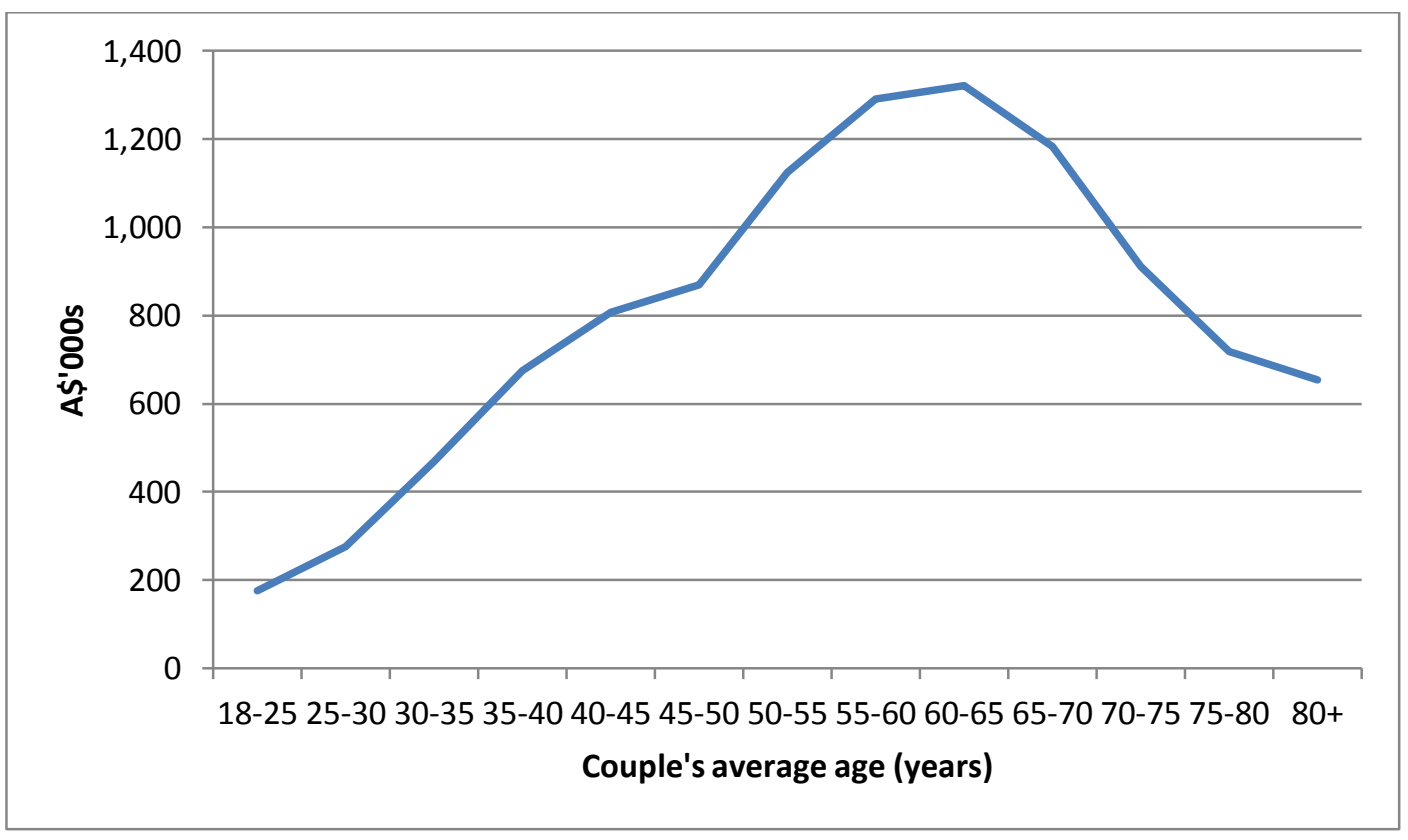

Table 1 presents the regression estimates for couple's net wealth. The average net wealth for the sample was $\$ 870,300$ in 2010 Australian dollars. The adjusted R-squared of around 13\% seems reasonable given the nature of the explanatory variable, and all control variables conform to expectations. The age variable used is the average of the husband and wife's age. Consistent with the $\mathrm{LCH}$, net wealth increases with age but at a declining rate. Taking the results for the simple OLS model, the coefficients on age and age-squared imply maximum wealth is reached at an average age of 43.6 years. Additionally, net wealth increases with the duration of the marriage, and is lower if the husband has previously been married, although this effect is only weakly significant. Wealth increases strongly with educational qualifications, especially the husband's; there is a substantial penalty if the wife is from a 
non-English speaking background and her English proficiency is poor (the effect of this is not significant for the husband), and either partner having a work-limiting disability reduces wealth. While years of work experience may potentially be endogenous to the number of children raised, this is most likely to be problematic in the case of the wife's labour force history. A variable capturing previous years of work experience has been included for the husband only, and the couple's net wealth is estimated to increase by around $\$ 32,000$ for each prior year in work. The estimates from the quantile regression follow a similar pattern.

The main parameter of interest is the effect of child-years. The coefficient on this variable is significant at the $5 \%$ level in the OLS model, and at the $1 \%$ level for each of the conditional estimates at the $0.25,0.5$ and 0.75 quantiles. The OLS estimate implies a decline in net wealth of just $\$ 1,400$ for each year in which a child lives with their parents. The quantile regressions generate slightly higher estimates of the decline in wealth with each 'child-year', and these increase from $\$ 1,600$ per year at the $25^{\text {th }}$ quantile to $\$ 1,900$ at the $50^{\text {th }}$ quantile and $\$ 2,400$ at the $75^{\text {th }}$ quantile. Thus, there is some evidence that the presence of children has a larger impact on net wealth accumulation at the upper end of the wealth distribution, in terms of absolute dollars (but not relative to net wealth). The F-test rejects the hypothesis that the coefficients on child-years are equal only in the case of the difference between the estimate at the $25^{\text {th }}$ and $75^{\text {th }}$ quantiles (at the $5 \%$ level).

Even the higher of these estimates of the annual impact of raising a child on net wealth stands in stark contrast to the estimates of the amount spent on a child each year, which typically exceed $\$ 10,000$. This contrast is all the more striking when it is considered that the estimates of the impact on wealth encompass any effect the child has on labour force participation of the mother, something that is ignored in expenditure based estimates but must surely be one of the major 'costs' associated with bringing up children. However, neither approach allows for the effect that having children or planning to have children may have had on the level of education attained by the parents. 
Table 1

OLS and quantile regression estimates for couples' net wealth (in \$’000s) - pooled 2002, 2006 and 2010 samples.

\begin{tabular}{|c|c|c|c|c|c|c|c|c|c|c|c|c|}
\hline \multirow[b]{4}{*}{ Intercept } & \multirow{2}{*}{\multicolumn{3}{|c|}{$O L S$}} & \multicolumn{9}{|c|}{ Quantile Regression } \\
\hline & & & & & $Q=0$. & & $Q=0$. & & & & $Q=0$. & \\
\hline & \multicolumn{2}{|c|}{ Coefficient } & \multirow{2}{*}{$\frac{S E}{185.3}$} & \multicolumn{2}{|c|}{ Coefficient } & \multirow{2}{*}{$\frac{S E^{c}}{33.4}$} & \multicolumn{2}{|c|}{ Coefficient } & \multirow{2}{*}{$\frac{S E^{c}}{75.7}$} & \multicolumn{2}{|c|}{ Coefficient } & \multirow{2}{*}{$\frac{S E^{c}}{133.2}$} \\
\hline & -1649.9 & $* * *$ & & -884.9 & $* * *$ & & -1189.2 & $* * *$ & & -1422.0 & $* * *$ & \\
\hline Wave 6 (2006) & 272.4 & $* * *$ & 30.6 & 84.0 & $* * *$ & 8.1 & 115.9 & $* * *$ & 13.3 & 176.1 & $* * *$ & 24.9 \\
\hline Wave 10 (2010) & 229.8 & $* * *$ & 31.3 & 99.7 & $* * *$ & 12.9 & 130.0 & $* * *$ & 14.9 & 181.7 & $* * *$ & 27.8 \\
\hline Couples' age & 50.8 & $* * *$ & 8.1 & 31.1 & $* * *$ & 1.6 & 45.8 & $* * *$ & 3.6 & 55.8 & $* * *$ & 6.4 \\
\hline Age squared & -0.6 & $* * *$ & 0.1 & -0.3 & $* * *$ & 0.0 & -0.5 & $* * *$ & 0.0 & -0.6 & $* * *$ & 0.1 \\
\hline Years current marriage & 6.8 & $* * *$ & 2.5 & 5.0 & $* * *$ & 0.7 & 7.4 & $* * *$ & 0.9 & 9.9 & $* * *$ & 1.9 \\
\hline Wife married before & 5.0 & & 47.4 & -4.7 & & 10.9 & 33.4 & $*$ & 17.1 & 88.5 & $* * *$ & 33.1 \\
\hline $\begin{array}{l}\text { Husband married before } \\
\text { Wife's' Highest Qual: }\end{array}$ & -82.9 & $*$ & 46.5 & -24.0 & & 16.1 & -15.7 & & 17.4 & -41.0 & & 25.3 \\
\hline University degree & 281.6 & $* * *$ & 39.3 & 122.4 & $* * *$ & 15.0 & 148.9 & $* * *$ & 23.6 & 233.5 & $* * *$ & 35.3 \\
\hline Diploma & 263.6 & $* * *$ & 46.9 & 118.8 & $* * *$ & 17.3 & 135.4 & $* * *$ & 22.0 & 250.7 & $* * *$ & 33.5 \\
\hline Certificate III/IV & 50.3 & & 42.9 & 12.3 & & 14.7 & 15.4 & & 24.1 & 45.2 & $* *$ & 22.9 \\
\hline Year 12/Cert I/II & 93.5 & $* *$ & 39.3 & 58.9 & $* * *$ & 14.0 & 81.3 & $* * *$ & 17.8 & 123.5 & $* * *$ & 22.7 \\
\hline Left before $\mathrm{Yr} 12^{\mathrm{a}}$ & - & & & - & & & - & & & - & & \\
\hline $\begin{array}{l}\text { Husb. Highest Qual: } \\
\text { University degree }\end{array}$ & 587.2 & $* * *$ & 41.4 & 225.0 & $* * *$ & 11.2 & 363.7 & $* * *$ & 22.5 & 575.5 & $* * *$ & 48.8 \\
\hline Diploma & 356.2 & $* * *$ & 48.3 & 145.2 & $* * *$ & 15.7 & 200.9 & $* * *$ & 18.6 & 270.4 & $* * *$ & 35.2 \\
\hline Certificate III/IV & 131.3 & $* * *$ & 34.7 & 84.4 & $* * *$ & 11.2 & 105.0 & $* * *$ & 15.9 & 117.9 & $* * *$ & 25.8 \\
\hline Year 12/Cert I/II & 343.3 & $* * *$ & 48.4 & 105.0 & $* * *$ & 11.9 & 136.2 & $* * *$ & 13.7 & 244.3 & $* * *$ & 34.0 \\
\hline $\begin{array}{l}\text { Left before } \mathrm{Yr} 12^{\mathrm{a}} \\
\text { Wife non-Eng bkgrnd: }\end{array}$ & - & & & - & & & - & & & - & & \\
\hline \& English good & -89.3 & & 75.2 & -45.2 & $* *$ & 21.3 & -93.4 & $* * *$ & 32.2 & -117.9 & $* *$ & 52.3 \\
\hline $\begin{array}{l}\text { \& English poor } \\
\text { Husband non-Eng bkgrnd: }\end{array}$ & -272.6 & $* *$ & 118.4 & -124.2 & $* * *$ & 34.2 & -213.0 & $* * *$ & 47.2 & -235.4 & $* * *$ & 77.0 \\
\hline \& English good & -28.4 & & 78.5 & -29.9 & & 21.3 & -2.3 & & 27.9 & -9.6 & & 47.3 \\
\hline \& English poor & -71.6 & & 132.7 & -39.4 & & 40.1 & 22.2 & & 55.9 & 18.2 & & 84.4 \\
\hline Wife has disability ${ }^{b}$ & -126.0 & $* * *$ & 35.5 & -52.2 & $* * *$ & 11.0 & -88.5 & $* * *$ & 17.4 & -121.4 & $* * *$ & 33.1 \\
\hline
\end{tabular}




\begin{tabular}{|c|c|c|c|c|c|c|c|c|c|c|c|c|}
\hline \multirow[b]{4}{*}{ Husband has disability ${ }^{b}$} & \multirow{2}{*}{\multicolumn{3}{|c|}{$O L S$}} & \multicolumn{9}{|c|}{ Quantile Regression } \\
\hline & & & & \multicolumn{3}{|c|}{$Q=0.25$} & \multicolumn{3}{|c|}{$Q=0.5$} & \multicolumn{3}{|c|}{$Q=0.75$} \\
\hline & \multicolumn{2}{|c|}{ Coefficient } & \multirow{2}{*}{$\frac{S E}{35.6}$} & \multicolumn{2}{|c|}{ Coefficient } & \multirow{2}{*}{$\frac{S E^{c}}{13.6}$} & \multicolumn{2}{|c|}{ Coefficient } & \multirow{2}{*}{$\frac{S E^{c}}{16.8}$} & \multicolumn{2}{|c|}{ Coefficient } & \multirow{2}{*}{$\frac{S E^{c}}{26.7}$} \\
\hline & -47.3 & & & -71.2 & $* * *$ & & -94.3 & $* * *$ & & -127.4 & $* * *$ & \\
\hline Years in work (husband) & 32.4 & $* * *$ & 2.5 & 11.2 & $* * *$ & 0.9 & 14.1 & $* * *$ & 1.2 & 21.5 & $* * *$ & 2.0 \\
\hline Total child years & -1.4 & $* *$ & 0.6 & -1.6 & $* * *$ & 0.2 & -1.9 & $* * *$ & 0.3 & -2.4 & $* * *$ & 0.4 \\
\hline $\begin{array}{l}\text { Mean/ Predicted value at mean } \\
\text { (dependent variable) }\end{array}$ & 870.3 & & & 349.7 & & & 601.9 & & & 988.9 & & \\
\hline Observations & 8,804 & & & 8,804 & & & 8,804 & & & 8,804 & & \\
\hline R-squared & 0.13 & & & & & & & & & & & \\
\hline Adjusted/psuedo R-squared & 0.13 & & & 0.1125 & & & 0.1303 & & & 0.1416 & & \\
\hline F-value & 59.1 & $* * *$ & & & & & & & & & & \\
\hline
\end{tabular}

Notes: a. includes persons who left before completing Year 12 and have no post-school qualifications; b. definition is restricted to a long term disability that limits type of work that can be done; c. bootstrap standard error.

${ }^{*} p<0.10, * * p<0.05, * * * p<0.01$ 
Table 2

OLS and quantile regression estimates for couples' change in net wealth (in \$’000s) - 2002 to 2006 and 2006 to 2010 (pooled).

\begin{tabular}{|c|c|c|c|c|c|c|c|c|c|c|c|c|}
\hline \multirow[b]{3}{*}{ Intercept } & \multirow{2}{*}{\multicolumn{3}{|c|}{$O L S$}} & \multicolumn{9}{|c|}{ Quantile Regression } \\
\hline & & & & \multicolumn{3}{|c|}{$Q=0.25$} & \multicolumn{2}{|c|}{$Q=0.5$} & $S E^{c}$ & \multicolumn{3}{|c|}{$Q=0.75$} \\
\hline & -346.2 & & $\begin{array}{c}S E \\
258.1\end{array}$ & -326.1 & $* * *$ & $\frac{S E^{c}}{73.7}$ & -215.3 & $* * *$ & 75.7 & 257.7 & & $\frac{S E^{c}}{123.3}$ \\
\hline Initial net wealth & -0.3 & $* * *$ & 0.0 & -0.4 & $* * *$ & 0.0 & -0.2 & $* * *$ & 0.0 & 0.1 & & 0.1 \\
\hline Wife retired from LF & -195.0 & $* * *$ & 62.2 & -35.6 & $* * *$ & 13.4 & -48.0 & $* * *$ & 13.6 & -76.0 & $* * *$ & 25.7 \\
\hline Husband retired from LF & -174.2 & $* * *$ & 67.3 & -40.1 & $* * *$ & 15.3 & -69.8 & $* * *$ & 21.6 & -128.8 & $* * *$ & 29.1 \\
\hline Home owner initially & 168.0 & $* * *$ & 49.3 & 132.0 & $* * *$ & 8.4 & 110.8 & $* * *$ & 17.6 & 53.7 & & 26.0 \\
\hline Years current marriage & 2.2 & & 3.2 & 1.5 & $* *$ & 0.7 & 1.4 & $*$ & 0.7 & 1.1 & & 1.2 \\
\hline Wife married before & -43.2 & & 61.5 & -1.1 & & 8.8 & -8.4 & & 15.1 & 3.2 & & 28.6 \\
\hline Husband married before & -1.7 & & 62.4 & 9.9 & & 11.7 & 16.8 & & 14.6 & -7.8 & $* * *$ & 28.3 \\
\hline \multicolumn{13}{|l|}{ Wife's' Highest Qual: } \\
\hline University degree & 129.9 & $* * *$ & 50.4 & 57.3 & $* * *$ & 15.0 & 88.1 & $* * *$ & 12.6 & 50.4 & & 28.9 \\
\hline Diploma & 80.9 & & 60.0 & 29.6 & $*$ & 16.4 & 25.4 & & 16.9 & 38.9 & & 24.3 \\
\hline Diploma & 71.4 & & 61.6 & 39.7 & $* *$ & 15.9 & 27.8 & & 19.5 & -30.6 & $* * *$ & 26.9 \\
\hline Certificate III/IV & 39.8 & & 45.0 & 28.8 & $* * *$ & 8.1 & 24.4 & $* *$ & 11.3 & -16.8 & $* * *$ & 20.1 \\
\hline Year 12/Cert I/II & 144.1 & $* *$ & 63.7 & 24.3 & $*$ & 14.5 & 21.9 & & 17.3 & 0.4 & $* * *$ & 32.7 \\
\hline Left before $\mathrm{Yr} 12^{\mathrm{a}}$ & - & & & - & & & - & & & - & & \\
\hline \multicolumn{13}{|l|}{ Wife non-Eng bkgrnd: } \\
\hline \& English good & 5.3 & & 98.5 & -39.4 & & 25.8 & -20.2 & & 31.4 & 23.8 & & 53.1 \\
\hline \& English poor & -59.4 & & 165.5 & -19.9 & & 29.0 & -51.6 & $*$ & 27.2 & -5.3 & $* * *$ & 53.5 \\
\hline
\end{tabular}




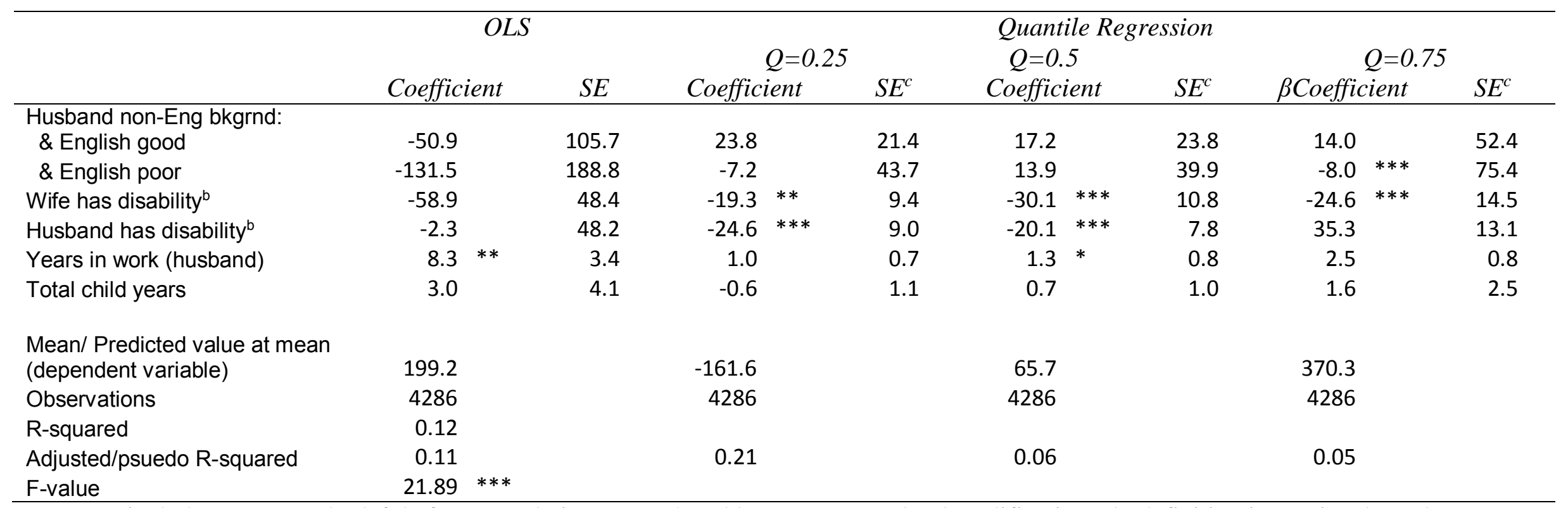

Notes: a. includes persons who left before completing Year 12 and have no post-school qualifications; b. definition is restricted to a long term disability that limits type of work that can be done; c. bootstrap standard error.

${ }^{*} p<0.10, * * p<0.05, * * * p<0.01$ 
As noted, a major limitation of this approach is the need to rely on a crude proxy for the accumulated number of years the couple has had dependent children living with them - in this case inferring 18 years for each child born to the wife. In estimating the change in net wealth between periods (model 2), the number of dependent children in residence in the household in the intervening years can be precisely determined. When pooled over the eight years, for $44 \%$ of observed couple-years there were no children present in the household, $16 \%$ had one child present, $25 \%$ two children, $11 \%$ three children and there were 4 or more children present for $4 \%$ of those observations. When the child-years are summed, $39 \%$ had no children present at any time across the four year intervals. Among those who were observed to have dependent children, the mode for the number of child-years is 8 , with a maximum value of 45 dependent child-years over a four year interval.

The range of control variables is also expanded to include initial wealth holding and homeownership status at the commencement of each 4-year period. The results from the OLS regression returned a positive impact of around $\$ 4,500$ for each dependent child-year on wealth accumulation. While this estimate was not statistically different from zero, it still suggests a remarkably low financial burden in a child. One possible explanation for this result is that the linear and quadratic age specification does not adequately capture retirement patterns, so that dissaving associated with retirement is partly reflecting a stage of the lifecycle in which couples are less likely to have dependent children. Hence variables to capture whether or not the wife and husband had retired were added to the covariates. Either partner having retired from the workforce has a substantive, statistically significant and negative association with wealth accumulation. As reported in Table 2, however, the results continue to show no negative impact upon wealth accumulation arising from the presence of children within the household. A negative coefficient on the number of dependent child-years is observed only for the estimate for the $25^{\text {th }}$ quantile, suggesting reduced wealth accumulation of $\$ 600$ for each year a dependent child is present, but again the estimate is not significantly different from zero.

These results are likely to be sensitive to institutional settings in Australia, including largely public health and education systems, and compulsory superannuation contributions by workers. As a form of forced saving, compulsory superannuation may suppress wealth differences between families, but will also accentuate wealth impacts of children to the extent that reduced labour force participation associated with raising children lowers superannuation contributions (superannuation holdings are included in the wealth measure). However, these 
estimates for Australia are in no way an aberration in the context of the findings of the two existing studies noted above from other countries which imply either a very small annual impact of children on net wealth in the US (Scholz \& Seshandri 2009) and a positive impact for married men and women in Sweden (Bolin \& Palsson 2001).

\section{(i) Tests of specification and sensitivity}

There are many potential variations to the models reported above, but scope to report only selected sets of results. A number of alternative specifications were tested, perhaps the most important of these to be modelling wealth in logarithmic rather than in linear form; and the inclusion or exclusion of years of work experience due to potential endogeneity between workforce participation and the presence of children. The resulting impact on the estimates for total child-years $\left(\gamma_{1}\right.$ and $\left.\gamma_{2}\right)$ under these and some other alternative specifications are discussed in this section.

It is common to model wealth or income distributions in logarithmic form rather than the dollar amounts. When the natural log of family net wealth at a point in time was used as the dependent variable in model 1, the adjusted R-squared improves markedly to 0.29 in the OLS regression. Moreover, the coefficients on child-years in the OLS and quantile regression are all highly significant. In the OLS regression the estimated $\gamma_{1}$ implies that each year a couple has a dependent child living with them reduces net wealth at the mean by $\$ 2,800$, and in the quantile regression $\$ 1,900, \$ 2,200$ and $\$ 2,500$ at the $25^{\text {th }}, 50^{\text {th }}$ and $75^{\text {th }}$ quantiles, respectively.

A drawback of the standard logarithmic specification is that the dependent variable is not defined for families with non-positive values of net wealth, resulting in the omission of 125 observations from the regression analysis. This would be of little concern if these were random omissions, but removing those with lowest net wealth risks biasing the results and hence the linear specification was preferred. To enable couples with negative net wealth to be included, a further $\log$ transformation was defined as $\ln (\mathrm{Y})$ for $\mathrm{Y} \geq \$ 3 ; 0$ for $-\$ 3<\mathrm{Y}<\$ 3$; and $-\ln (\mathrm{Y})$ for $\mathrm{Y} \leq-\$ 3$. The adjusted $\mathrm{R}$-squared is in fact lower using this transformation $(0.12)$ than with the linear specification, although again all estimates of $\gamma_{1}$ are highly significantly different from zero. The OLS regression now implies each child-year reduces wealth by $\$ 3,500$ at the mean of the dependent variable, and by $\$ 2,000, \$ 2,200$ and $\$ 2,600$ at the $25^{\text {th }}$, $50^{\text {th }}$ and $75^{\text {th }}$ quantiles, respectively. 
For the models of the four-yearly change in net wealth, omitting non-positive values is even more problematic, and results in the loss of around $30 \%$ of the sample for estimation. In any case, all models tested with logarithmic transformations of the change in net wealth continue to show either a positive or insignificant impact of children on wealth accumulation.

The estimates of $\gamma_{1}$ reported for model 1 are robust to inclusion or exclusion of the number of years in paid work for either the husband or wife - estimates of the impact of dependent child-years on net wealth in the models vary by no more than $\$ 400$ across the models. As anticipated, the estimates of the impact of raising children on net wealth are lower when the mother's labour force history is included, as lower levels of (age-specific) work experience are correlated with child rearing. The estimates remain insignificant for the models of change in net wealth.

Additionally, the results are insensitive to the measure of the age of the couples. In the models reported above this was based on the average age of the couple. Models using the husband's age instead of average age, and including both the husband's and wife's age (and their quadratics) separately were tested. Restricting the sample to persons aged 60 and below similarly had little impact on the findings. For the models of the change in wealth it is also possible to include age-specific child-years. There was evidence from these models that the presence of young children (0-4 years) is conducive to wealth accumulation, but estimates for children aged 5-9 years, 10-14 years and children aged 15 years and older were insignificant.

Finally, a common challenge we have encountered to this approach is that it ignores the likelihood that couples' savings are partly determined by their fertility intentions: that is, they accumulate wealth in anticipation of having children. In fact the effect of this will be to compound the estimated negative impact of children on net wealth. This is because it raises savings in years without children, with associated dissavings upon arrival of the child, or at least a levelling off in the rate of wealth accumulation. To the extent couples do have higher savings in anticipation of having children, the estimates of $\gamma_{1}$ and $\gamma_{2}$ will overstate the full impact of children on net wealth.

\section{Discussion}

Typical estimates of the amount of money Australian parents do spend on their children, or 'need to spend', exceed A $\$ 10,000$ per child per annum in today's dollars with recent 
estimates as high as $\$ 19,300$. Such estimates ignore the cost of foregone earnings due to lower labour force participation, which is most relevant to mothers' potential earnings. Breusch and Gray (2004) suggest a further 31 percent of a women's lifetime income, or $\$ 247,000$, could be added to account for Australian mothers' foregone earnings for one child and an additional $\$ 103,000$ for a second child, implying a further cost of around $\$ 13,000$ per child per annum for a 2-child family. Such studies also tend to exclude child-care costs. All in all, these computations suggest a financial impost upon parents in the vicinity of $\$ 30,000$ per child per year relative to couples with no children.

In contrast, the estimates presented in this paper indicate that the wealth of couples is reduced by, at most, around $\$ 2,000$ for each dependent-child year. Recalling the identity that income in a period must equal consumption plus savings, increased expenditure and foregone income associated with children must also equate to lower savings and wealth. How can we possibly reconcile these starkly divergent estimates of the financial impost of children upon their parents? The charge that the net wealth regressions suffer from selection bias arising from wealthier parents being more likely to have children, or to have more children, can be dismissed since fertility is inversely related to income and, in any case, the models of couples' change in net wealth control for this.

It is true that children will often have positive effects on the income side of the equation, notably through welfare payments and tax concessions, an impact which is appropriately captured in the net-wealth approach but ignored in expenditure-based approaches. However, it seems unlikely this would more than compensate for foregone earnings. Rather, we believe it is the interaction between the presence of children in the home, income and utility that holds the key to explaining this paradox.

As noted above, previous authors have adopted a utility perspective to point out the need to account for benefits of children as well as the costs when making welfare comparisons between families. In this spirit, Deaton and Muellbauer (1986, p. 725) note that parents may derive utility from their own and their children's consumption: "That parents choose to have children means that the benefits of having them are greater than the costs, but it does not mean that the costs are zero". We concur with these sentiments in as far as they suggest expenditure-based approaches may over-estimate the compensation required to maintain parental welfare constant. However, that does not fully reconcile the obvious incompatibility 
between the large estimates of what parents spend on their children and the minimal impact upon net wealth.

We suggest two further effects likely to be important. The first is that children are complementary to activities that are not income intensive and less subject to rivalry or 'conspicuous consumption' (Frank 1999). When children are present, nights at home with the family, a simple visit to the park, or watching your child play sport may provide enjoyment that would otherwise be gained through income-intensive pursuits, such as holidays and restaurants. This is more than a direct substitution effect - parents' own utility may increase at a lower level of consumption expenditure. Second, the value of non-market production within the household may increase substantially in the presence of children. Parents, in particular mothers, will increase their time spent cooking, cleaning, laundry, home decorating, teaching, entertaining and so on. Expenditure-based approaches would not capture the value of any such increase in non-market production but, to the extent this substitutes for market consumption, it will be reflected in the net wealth approach.

We concord with the view put by others that the concept of the 'cost' of a child is ambiguous, and argue that the emphasis placed in the existing literature on such estimates is misplaced. Rather, the important issue is of the financial capacity of families to meet the resource requirements of raising children, for which relevant measures might variously be described as affordability, financial stress or financial wellbeing. The net-wealth approach offers a different perspective on the affordability of children and one that is intuitively more appealing than expenditure-based approaches on a number of fronts, notably by accounting for income effects and for the potential that the benefits of children substitute for other consumption. The net-wealth approach has clear relevance for decision-making in social policy settings and for those contemplating family formation. The results challenge the common perception that children are a large financial burden. It appears that under Australia's existing institutional, taxation and social security arrangements, couple families who have children enjoy a roughly similar standard of living as couples without children, although they may allocate their expenditure very differently. And those couples contemplating starting or extending a family generally need not be put off by financial concerns. In spite of the very high expenditure-based estimates, even those on a low income can afford to have children, and to raise them comfortably. In these practical senses, and in the context of a relatively wealthy country such as Australia, the results from the net-wealth 
approach do challenge the extent to which expenditure based estimates relate, in any meaningful way, to couples' financial capacity to raise a family.

\section{REFERENCES}

Banks, J., Blundell, R. and Preston, I.P. (1994), 'Life-cycle expenditure allocations and the consumption costs of children', European Economic Review, 38, 1391- 1410.

Bolin, K. and Palsson, A. (2001), 'Male and female wealth: The importance of the family structure', 21st Arne Ryde Symposium on Non-Human Wealth and Capital Accumulation, Department of Economics, Lund University, Lund, Sweden..

Bradbury, B. (2008), 'Time and the cost of children', Review of Income and Wealth, 54(3), 305-322.

Brandrup, J.D. and Mance, P. (2010), 'Changes in household expenditure associated with the arrival of newborn children', Australian Social Policy Journal, 9, 41-66.

Breusch, T. and Gray, E. (2004), 'New estimates of mothers' foregone earnings using HILDA data' Australian Journal of Labour Economics, 7(2), 125-150.

Browning, M. and Ejrnæs, M. (2009), 'Consumption and children', Review of Economics and Statistics, 91(1), 93-111.

Case, A., Lubotsky, D. and Paxson, C. (2002), 'Economic status and health in childhood: The origins of the gradient', American Economic Review, 92(5), 1308-1334.

Commission on Social Determinants of Health (2008), Closing the gap in a generation: Health equity through action on the social determinants of health, Final Report of the Commission on Social Determinants of Health. World Health Organization, Geneva.

Deaton, A. (2005), 'Franco Modigliani and the Life Cycle Theory of consumption' Banca Nazionale del Lavoro Quarterly Review, 58(233-234), 91-107.

Deaton, A. and Muellbauer, J. (1986), 'On measuring child costs: With applications to poor countries' Journal of Political Economy, 94(4), 720-744.

Ferreira, M.L., Buse, R.C. and Chavas, J.P. (1998), 'Is there bias in computing household equivalence Scales', The Review of Income and Wealth, 44(2), 183-198. 
Frank, R.H. (1999), Luxury fever. The Free Press, New York.

Garvey, E., Murphy E. and Osikoya P. (2011), 'Estimates of the cost of a child in Ireland', (Combat Poverty Agency Working Paper Series 11/0).

Gray, M. and Stanton, D. (2010), 'Costs of children and equivalence Scales: A review of methodological issues and Australian estimates', Australian Journal of Labour Economics 13(1), $99-115$.

Henman, P. (2008), 'Australian costs of raising children: Updated costs of raising children March Quarter 2008', (Social Policy Unit, University of Queensland). Available from http://www.uq.edu.au/swahs/costsofkids/CostsofRaisingChildrenMarchQuarter08.pdf

Hertzman, C. (1999), 'Population health and human development', in Keating, D.P. and Hertzman, C. (eds), Developmental health and the wealth of nations: Social, biological, and educational dynamics. The Guilford Press, New York; 21-40.

Koenker, R. and Bassett, G. W. (1978). Regression quantiles. Econometrica, 46, 33-50.

Koenker, R. and Hallock, K. (2001). Quantile regression: An introduction. Journal of Economic Perspectives, 15(4), 143-156.

Lino, M. (2012), 'Expenditure on children by families, 2011', (U.S. Department of Agriculture, Center for Nutrition Policy and Promotion, Miscellaneous Publication No. 15282011). Available from http://www.cnpp.usda.gov/Publications/CRC/crc2011.pdf LV= (2012), 'Cost of a child from cradle to college, 2012 Report'. Available from http://www.lv.com/upload/lv-rebrand-2009/pdfs/other/11665_LV_COAC.PDF. McDonald, P. (1990), 'The costs of children: A review of methods and results', Family Matters, 27, 19-22.

Modigliani, F. (1986), 'Life cycle, individual thrift, and the wealth of nations' American Economic Review, 76(3), 297-313.

Modigliani, R. and Brumberg, R. (1954), 'Utility analysis and the consumption function: An interpretation of cross-section data', in Kurihara, K.K. (ed), Post Keynesian economics. Rutgers University Press, New Brunswick, NJ; 388-436.

NATSEM (2013), 'Cost of kids: The cost of raising children in Australia' AMP.NATSEM Income and Wealth Report Issue 33. 
Nomaguchi, K.M. and Milkie, M.A. (2003), 'Costs and rewards of children: The effects of becoming a parent on adults' lives' Journal of Marriage and Family, 65(2), 356-374.

Percival, R. and Harding, A. (2002). All they need is love ... and around $\$ 450,000$. AMP.NATSEM, Income and Wealth Report Issue 3.

Percival, R. and Harding, A. (2005), 'The estimated costs of children in Australian families in 2005-06', Commissioned research report for the Ministerial Task Force on Child Support.

Percival, R. and Harding, A. (2007), 'Australian child costs in 2007: Honey I calculated the kids ... its \$537,000’ AMP.NATSEM, Income and Wealth Report Issue 18.

Pollak, R. and Wales, T. (1979), 'Welfare comparisons and equivalence scales' American Economic Review, 69(2), 216-221.

Saunders, P. (1999), 'Budget standards and the poverty line' The Australian Economic Review, 32(1), 43-61.

Scholz, J.K. and Seshadri, A. (2009), 'Children and household wealth'. Working Paper (University of Wisconsin - Madison).

Valenzuela, R. (1999), 'Costs of children and living standards in Australian households', Australian Social Monitor, 2(2), 31-36.

Watson, N., and Wooden, M. (2010), 'The HILDA Survey: Progress and future developments' The Australian Economic Review, 43, 326-336.

Whiteford, P. (1985), ‘A family's needs: Equivalence scales, poverty and social security’, Research Paper 27 (Department of Social Security, Canberra). 